\title{
El Síndrome de Prader-Willi: Características Cognitivas e Implicaciones Educativas
}

\section{The Prader-Willi Syndrome: Cognitive Characteristics and Educative Implications}

\author{
Lourdes Martínez Pérez \\ Universidad Complutense de Madrid
}

\author{
Jorge Muñoz-Ruata \\ Fundación Promiva
}

\author{
Emilio García García \\ Universidad Complutense de Madrid
}

Resumen. Se estudian las características cognitivas del Síndrome Prader-Willi (SPW). Se han evaluado 10 sujetos con el WISC-R y el ITPA. Se han dividido los sujetos en tres grupos mediante la técnica K-means, realizando posteriormente un análisis de Kruskal-Wallis para la caracterización de los tres grupos. Las características de estos grupos se acomodan a las descritas en la literatura para los tres grupos genéticos principales del SPW. El primer grupo presenta características similares a las descritas en los disómicos: buenas habilidades verbales, tanto expresivas como comprensivas, y rasgos dispráxicos. El segundo grupo se acomodan a las características de las deleciones cortas, con un perfil homogéneo de deficiencia mental ligera y predominio de las habilidades práxicas; sus habilidades lingüísticas comprensivas son superiores a las expresivas. El tercer grupo se acomoda a las características de la deleción larga, con un nivel homogéneo dentro de deficiencia mental media y deterioro de las habilidades tanto expresivas como comprensivas. Se comentan algunos principios y estrategias para la intervención educativa.

Palabras clave: Síndrome de Prader-Willi, deficiencia mental, cognición, lenguaje, disomía, deleción.

Summary. This study analyses the cognitive characteristics of Prader-Willi Syndrome (SPW). Ten SPW patients with WISC-R and ITPA were evaluated. Subjects were divided into three groups using the K-means method and a Kruskal-Wallis analysis was later carried out, in order to characterize the three groups. The characteristics of these three groups are in accordance with those described in the literature for the three main genetic groups of SPW. The first group shows similar characteristics for those described in people with disomy: good verbal abilities, both expressive and comprehensive, as well as dispraxic features. The second group coincides with the characteristics of short deletions, with a homogeneous profile of slight mental retardation and a predominance of praxic abilities; their comprehensive linguistic abilities are higher than their expressive abilities. The third group matches the characteristics of long deletion, with a homogeneous level of average mental retardation and deterioration of expressive and comprehensive abilities. Some principles and strategies are discussed for the purpose of educational intervention.

Key words: Prader-Willi Syndrome, mental retardation, genetics, knowledge, language, disomy, deletion.

La correspondencia sobre este artículo debe enviarse a la primera autora a la Fundación Promiva. Carretera de Boadilla $\mathrm{N}^{\circ} 100.28220$ Majadahonda. E-mail: lmartinez@cop.es
Agradecimientos: Este estudio ha sido financiado íntegramente por la Fundación Promiva. 


\section{Introducción}

El síndrome de Prader-Willi (SPW) fue descrito por primera vez en Hospital Infantil de Zurich, por Prader, Labhart y Willi, en 1956. Forma parte del grupo de las enfermedades raras de origen genético, ya que su prevalencia se estima entre $1 / 10.000$ al 1/15.000 personas. Es un trastorno que deriva de la ausencia de la actividad normal de los genes paternos del cromosoma 15, en las regiones q11.q12.q13. Se han identificado varias formas de alteración: Deleción "de novo" en el cromosoma 15; Disomía uniparental del cromosoma 15 materno; Alteración de la impronta y otras reorganizaciones cromosómicas.

Deleción "de novo" en el cromosoma 15. Se produce por la ausencia de genes en el brazo largo del cromosoma 15 heredado del padre. Se da en un $70 \%$ de los casos. El riesgo de tener otro hijo afectado es de un 1\%. Nicholls y Knepper (2001) y Mewborn, Milley, Fantes, Brown, Butler, Christian, y
Ledbetter, (2002) identificaron dos clases de deleción: una corta y otra más larga en la que se pierden 500 Kilobases más de material genético. (ver figura 1).

Disomía uniparental del cromosoma 15 materno. Se produce cuando los dos alelos del cromosomas 15 son heredados de la madre, de forma que no hay alelo paterno. Esta alteración se encuentra en el $25 \%$ de los afectados. El riesgo de recurrencia es bajo, un $1 \%$.

Alteración de la impronta. Error por el cual, a pesar de estar presentes tanto los genes paternos como los maternos en la línea germinal, no se borra la marca de la impronta que determina de qué progenitor proceden los genes. Este fenómeno se atribuye a una mutación en el mecanismo de la impronta que regula la activación de los genes paternos en la región 15q11-13 (Butler, 1995) lo que trae como consecuencia que estos genes se inactiven. Sólo entre un 3-5\% de los afectados con SPW presentan esta alteración. En el caso de esta mutación el riesgo de recurrencia es alto, de un $50 \%$.

Figura 1. Mapa genético de la región 15q-q13 del cromosoma 15 humano. Los límites más comunes de las deleciones (BP1- BP2 y BP3) se muestran con líneas en zigzag. Las flechas verticales señalan las regiones comprometidas en las deleciones y en la impronta. Traducido de Bittel, Kibiryeva, Butler (2007). Región afectada por la impronta tomada de Kokkonen (2003)

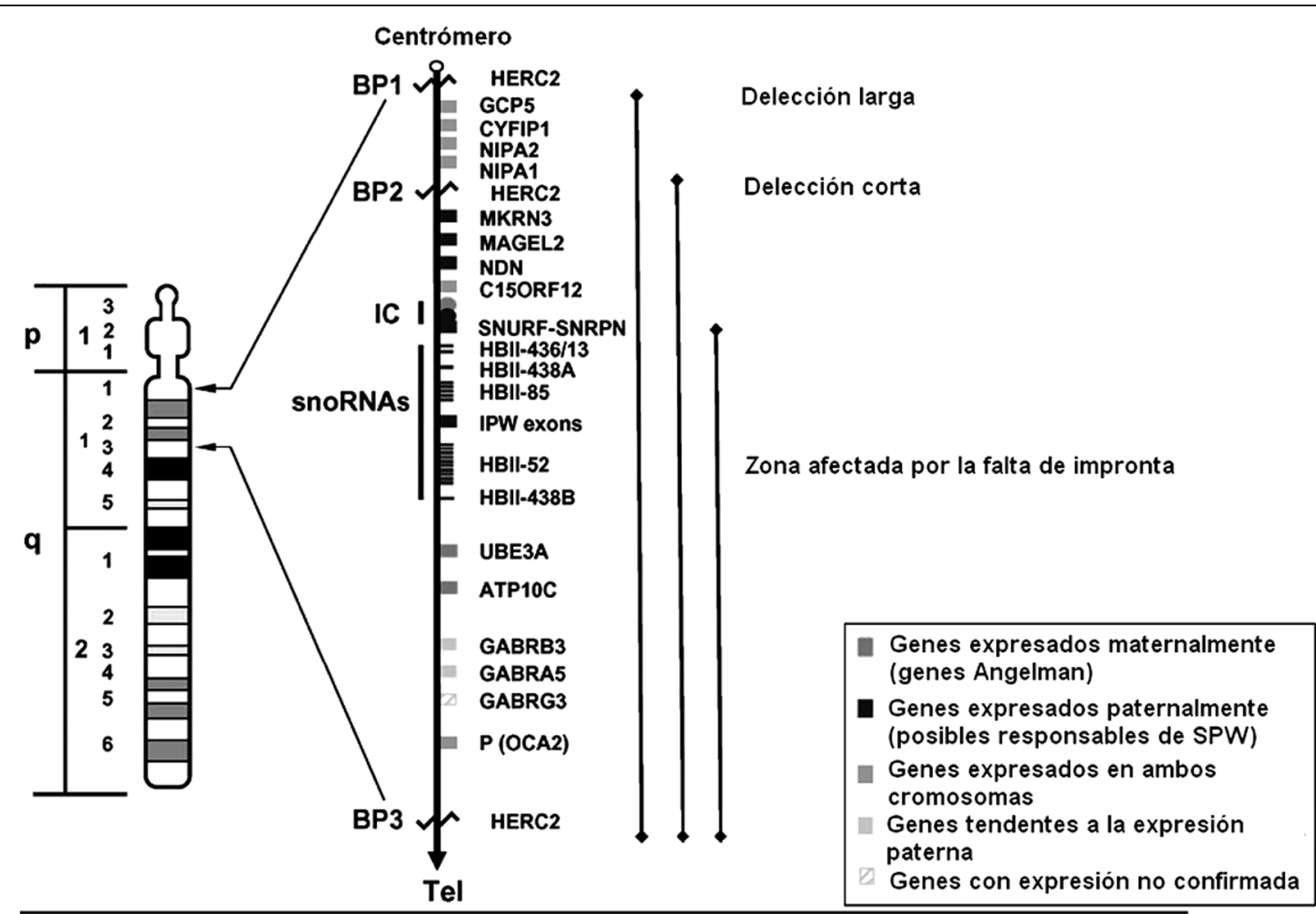


Otros tipos de alteraciones como las reorganizaciones cromosómicas (translocaciones, inversiones, etc.) se dan en un $1 \%$ de los afectados.

Los datos de incidencia indicados anteriormente están generalmente aceptados, aunque en un trabajo de Whittington, Butler y Holland (2007), en el que analizaban una muestra inglesa relativamente amplia, se encontró una variación en la proporción entre deleción y disomía que en la actualidad es de un 50\% para cada una. Atribuyen esta variación a un incremento de la edad materna en el momento de la concepción.

El SPW presenta aspectos físicos y psicológicos particulares, con características dismórficas, hiperfágia que produce obesidad, hipogonadismo, con el consecuente retraso o incompleto desarrollo puberal, baja estatura, sensibilidad al dolor disminuida, rascado compulsivo, trastornos del ritmo circadiano vigilia-sueño, deficiencia mental en diversos grados, y un fenotipo conductual variable. Las personas con el SPW son descritas como testarudas, astutas, manipuladoras, irritables, de humor lábil, coléricas, tendentes a explosiones temperamentales y ataques de rabia que pueden incluir agresividad hacia si mismos y hacia otros, perseverativos, centrados en si mismos y exigentes. La mentira y el hurto también son frecuentes junto con posibles dificultades emocionales e interpersonales. Estos síntomas pueden complicarse con alteraciones psicopatológicas más graves.

El fenotipo se presenta con distinto grado de severidad según los sujetos. Sus capacidades pueden variar desde una inteligencia normal en un $5 \%$, a una deficiencia mental profunda en el $6 \%$ de los sujetos. Diferentes aspectos del entorno, la cultura y el medio también condicionan la evolución diferenciada de estos sujetos, lo que explica, en parte, la existencia de una gran disparidad entre cada una de estas personas, que pese a ello poseen numerosos rasgos comunes.

Para estudiar el perfil cognitivo de SPW se han realizado numerosos estudios para determinar si existía un perfil cognitivo del síndrome, los primeros trabajos estaban orientados a buscar un perfil único, posteriormente con el desarrollo de los estudios genéticos se empezó a buscar distintos perfiles entre disómicos y deleción y últimamente también se han buscado las diferencias entre disómicos, deleción corta y deleción larga.

Dentro del primero grupo, que buscan perfiles únicos, encontramos los trabajos de Curfs, Wiegers, Sommers, Borghgraef y Fryns (1991) quienes estudiaron a 26 sujetos con SPW a los que administraron la escala de Inteligencia de Wechsler. Las puntuaciones fueron dispares, 10 sujetos obtuvieron las mayores puntaciones en el subtest de cubos, 5 en claves y laberintos, y otros puntuaban mejor en el cociente verbal (CIV). A pesar de los resultados los autores concluyen que el SPW se caracteriza por un buen rendimiento en tareas visoespaciales. También Conners, Rosenquist, Atwell y Klinger. (2000) estudiaron nueve adultos con SPW y no encontrando evidencia de que el procesamiento visual era superior al auditivo.

La mejora y generalización de las pruebas genéticas permitió realizar trabajos con una mayor diferenciación entre los grupos genéticos. Roof, Stone, MacLean, Feurer, Thompson, y Butler (2000) estudiaron a un grupo de SPW en función de los subtipos genéticos. Se les administró las escalas Wechsler y encontraron que los que padecían disomía uniparental materna tienen un mejor CIV que los que padecían deleciones. Los subtest en los que puntaban mejor eran información, aritmética, vocabulario y comprensión. No encontraron diferencias significativas entre los cocientes manipulativos de ambos grupos.

Por su parte Gross-Tsur, Landau, Benarroch, Wertman-Elad y Shalev (2001) analizaron el perfil cognitivo y el rendimiento académico de 18 niños con SPW. Todos ellos tenían grandes dificultades en aritmética y en escritura. No encontraron relación entre los genotipos y los déficits cognitivos.

Whittington, Holland, Webb, Butler, Clarke y Boer (2004) compararon a escolares con SPW por deleción, otros con disomía uniparental materna y un tercer grupo que presentaba trastornos de aprendizaje en un test de inteligencia y de rendimiento 
académico. La media del CIT de estos grupos fue de 60. Los sujetos con disomía tenían un mejor nivel verbal aunque eran peores en habilidades de codificación (claves). Muchos sujetos con deleción tenían buenas capacidades visoespaciales, aunque como conjunto no se diferenciaban significativamente de los sujetos con trastorno de aprendizaje. Los autores proponen como hipótesis que las diferencias cognitivas pueden deberse a que la disomía y la deleción no comprometen exactamente los mismos genes.

Walley y Donaldson (2005) estudiaron a 18 adultos con SPW, de los cuales 12 presentaban deleción y 6 disomía uniparental, y los compararon con 15 sujetos control, de edad similar en tareas de habilidad verbal, funciones ejecutivas y dígitos directos. No encontraron diferencias en las tareas ejecutivas. El subtipo con deleción fue significativamente peor en dígitos directos, aunque presentó una tendencia a realizar mejor la tarea de planificación visoespacial "Torre de Londres". Esta tendencia no alcanzó la significación estadística. Los autores concluyen que las personas con SPW no presentan un déficit específico en las funciones ejecutivas por lo que es un error atribuir sus trastornos de conducta a esta causa.

El grupo argentino de Abraldes, Torrado, Bin, Chertkoff, Baialardo y Waisburg (2007) en un análisis de 27 pacientes con SPW, 15 con deleción y 12 con disomía uniparental materna, de edades comprendidas entre 4 y 19 años, encontró que los sujetos con disomía obtienen unas puntuaciones significativamente más altas en el CIV que los que tienen deleción. Sin embargo no se encontraron diferencias entre los cocientes manipulativos (CIM).

Otras investigaciones proponen distinguir las características cognitivas entre los sujetos con deleciones corta y larga, posiblemente pensando en las 500 Kilobases de información que las diferencian. Butler, Bittel, Kibiryeva, Talebizadeh y Thompson (2004) fueron los pioneros en comparar las características cognitivas de los tres grupos etiológicos que reúnen a la mayoría de los sujetos con SPW: disomía uniparental materna, deleción larga y deleción corta. Los sujetos con deleción tuvieron peores resultados que los disómicos en la escala de Wechsler, aunque las diferencias solo fueron significativas al comparar las disomías con las deleciones largas. Los disómicos fueron mejores en el CIV, en cambio los sujetos con deleción corta eran superiores en rompecabezas. En general estos últimos obtuvieron mejores resultados en las medidas de procesamiento visual que los otros grupos. Los sujetos con deleción larga presentaban mayores complicaciones conductuales y un menor nivel de habilidades intelectuales que los otros dos grupos.

Como vemos, en los trabajos comentados los resultados en el estudio de las funciones cognitivas del SPW han sido diversos y a veces dispares. El artículo de Butler, Bittel, Kibiryeva, Talebizadeh y Thompson (2004), al considerar los tres grupos etiológicos principales, permitió dar una explicación a los resultados tan variables que presentaban los alumnos con el SPW que han pasado por nuestro centro, ya que unos tenían muy buenas capacidades lingüísticas mientras otros carecían prácticamente de lenguaje, unos eran dispráxicos mientras otros conservaban relativamente sus praxias, extrañándonos que dentro de un mismo síndrome hubiese características tan distintas.

Este trabajo pretende explorar y si es posible describir el perfil o perfiles cognitivos de un grupo de jóvenes con el SPW para comprobar si, tal y como se desprende del trabajo de Butler, Bittel, Kibiryeva, Talebizadeh y Thompson (2004), en nuestra muestra se pueden diferenciar tres grupos de características cognitivas diferentes que correspondan aproximadamente a las descritas por estos autores para cada uno de los grupos genéticos, o bien, tal y como se supone en otros trabajos, no hay diferencias significativas entre los sujetos con SPW, o si solo la hay entre los sujetos que padecen deleción y disomía. Si como sucede en los trabajos de Roof, Stone, MacLean, Feurer, Thompson y Butler (2000), Whittington, Holland, Webb, Butler, Clarke y Boer (2004), Walley y Donaldson (2005) y Abraldes, Torrado, Bin, Chertkoff, Baialardo y Waisburg (2007) los sujetos con disomía uniparental presentan un CIV significativamente mas alto que los que padecen deleción, en nuestra muestra debería haber alrededor 
de una cuarta parte de sujetos con esta característica. Debido a la rareza del síndrome nuestra muestra es forzosamente reducida.

\section{Método}

\section{Sujetos}

Se han evaluado las capacidades cognitivas de 10 sujetos, 2 varones y 8 mujeres, afectados del SPW y con edades comprendidas entre 13 y 16 años. Se desconoce el tipo genético al que pertenecen debido a que la muestra ha sido recogida durante 10 años, lo que ha provocado que se haya perdido el contacto con la mayor parte de los sujetos tras la terminación de su periodo escolar.

\section{Procedimiento}

Todos ellos fueron evaluados con la Escala de Wechsler para Niños (WISC-R) y el Test de Illinois de Habilidades Psicolingüísticas (ITPA) para determinar sus niveles cognitivos.

Con los datos obtenidos en las dos pruebas se ha realizado un análisis de "Clusters" con el procedimiento "K-means" para obtener tres grupos máximamente diferenciados que contuviesen sujetos con el mayor parecido posible entre sí. Tras la estadística descriptiva se han realizado análisis no paramétrico de las diferencias entre los tres grupos y comparaciones múltiples entre los grupos dos a dos, para estudiar las diferencias que los caracterizan.

\section{Resultados}

Como puede verse en la tabla 1, la media de los cocientes de la muestra total son relativamente homogéneos. Obsérvese sin embargo que la desviación estándar del CIV es de 20,98 lo que indica que los rendimientos verbales tienen una variabilidad mayor que la normal.
La tabla 1 muestra también las medias en cocientes de los tres grupos obtenidos con el análisis de “cluster". La comparación de los cocientes de estos grupos mediante un análisis de Kruskal-Wallis (ver tabla 2) muestra diferencias significativas en el CIV $(\mathrm{p}=0,04)$ y próximas a la significación en el CIT $(\mathrm{p}=$ $0,086)$.

La comparación Kruskal-Wallis de los subtest del WISC-R de los tres grupos aparecen diferencias significativas en Semejanzas, Aritmética, Comprensión Psicosocial, Cubos y Laberintos. En el ITPA hay diferencias significativas, entre los tres grupos, en una prueba claramente verbal: la comprensión auditiva (ver tabla 2).

Si embargo en la comparación de los grupos dos a dos con la U de Mann-Whittney (ver tabla 1) muestra diferencias significativas que podemos resumir de la siguiente manera: el grupo 1 es el más heterogéneo con capacidades verbales normales y muchos rasgos dispráxicos. Sus tres cocientes son muy dispares, el CIT corresponde a una deficiencia mental límite, el CIV se sitúa en el rango de la normalidad y el CIM corresponde a una deficiencia mental media.

Los tres cocientes del grupo 2 se sitúan en el rango de una deficiencia mental ligera. No hay diferencias significativas entre sus cocientes aunque su CIM está cinco puntos por encima de su CIV.

El grupo 3 tiene también cocientes homogéneos que los sitúan el rango de una deficiencia mental media (ver tabla 1).

En la comparación de los subtest (ver tabla 1) observamos que el grupo 1 es mejor que el grupo 3 en todos los subtest verbales y en laberintos. El grupo 2 es mejor que el 3 en los subtest de aritmética y comprensión del factor verbal y en cubos y laberintos del manipulativo. El grupo 1 es significativamente mejor que el 2 en los aspectos verbales de comprensión y aritmética, mientras que el 2 lo es en cubos.

El grupo 1 es superior a los grupos 2 y 3 en expresión verbal (fluidez léxica), (ver tabla 1). En comprensión auditiva los grupos 1 y 2 están prácticamente igualados siendo ambos claramente superio- 
Tabla 1. Estadísticos descriptivos y comparaciones entre grupos SPW dos a dos

\begin{tabular}{|c|c|c|c|c|c|c|}
\hline \multirow{3}{*}{ WISC-R } & \multirow[b]{3}{*}{ Grupo } & \multirow[b]{3}{*}{ Media } & \multirow[b]{3}{*}{ D.S. } & \multirow[b]{3}{*}{$\mathrm{N}$} & \multicolumn{2}{|c|}{$\begin{array}{l}\text { Comparaciones entre grupos } \\
\text { U de Mann -Whittney }\end{array}$} \\
\hline & & & & & Grupo 1 & Grupo 2 \\
\hline & & & & & $\mathrm{p}$ & $\mathrm{p}$ \\
\hline \multirow[t]{4}{*}{ CIT } & 1 & 71,50 & 23,33 & 2 & & \\
\hline & 2 & 59,33 & 8,96 & 3 & ,295 & \\
\hline & 3 & 45,00 & 8,12 & 5 & 031 & ,139 \\
\hline & Total & 54,60 & 15,16 & 10 & & \\
\hline \multirow[t]{4}{*}{ CIV } & 1 & 98,00 & 22,62 & 2 & & \\
\hline & 2 & 62,00 & 7,55 & 3 &, 010 & \\
\hline & 3 & 51,60 & 7,82 & 5 & ,002 & ,242 \\
\hline & Total & 64,00 & 20,98 & 10 & & \\
\hline \multirow{4}{*}{ CIM } & 1 & 50,50 & 14,84 & 2 & & \\
\hline & 2 & 67,67 & 9,45 & 3 &, 147 & \\
\hline & 3 & 51,20 & 11,54 & 5 & ,944 & ,092 \\
\hline & Total & 56,00 & 12,97 & 10 & & \\
\hline \multicolumn{7}{|l|}{ Subtest WISC-R } \\
\hline \multirow[t]{3}{*}{ ARITMÉTICA } & 1 & 9,00 &, 000 & 2 & & \\
\hline & 2 & 2,33 &, 000 & 3 &, 000 & \\
\hline & 3 & 1,00 & 1,528 & 5 &, 000 &, 060 \\
\hline \multirow[t]{3}{*}{ VOCABULARIO } & 1 & 9,50 & 6,364 & 2 & & \\
\hline & 2 & 4,67 & 2,082 & 3 & , 128 & \\
\hline & 3 & 3,20 & 2,049 & 5 &, 044 &, 534 \\
\hline \multirow[t]{3}{*}{ COMPRENSIÓN } & 1 & 10,00 & 2,828 & 2 & & \\
\hline & 2 & 4,33 &, 577 & 3 &, 003 & \\
\hline & 3 & 1,80 & 1,095 & 5 &, 000 &, 041 \\
\hline \multirow[t]{3}{*}{ CUBOS } & 1 & 2,00 &, 000 & 2 & & \\
\hline & 2 & 7,00 & 1,732 & 3 &, 002 & \\
\hline & 3 & 1,60 &, 894 & 5 & 689 &, 000 \\
\hline \multirow[t]{3}{*}{ LABERINTOS } & 1 & 12,00 & 1,414 & 2 & & \\
\hline & 2 & 13,00 & 1,732 & 3 & ,640 & \\
\hline & 3 & 3,60 & 2,608 & 5 & ,003 &, 001 \\
\hline \multicolumn{7}{|l|}{ ITPA } \\
\hline \multirow[t]{3}{*}{ COMP. AUDITIV. } & 1 & 44,00 &, 000 & 2 & & \\
\hline & 2 & 44,33 & 4,726 & 3 & ,970 & \\
\hline & 3 & 24,80 & 12,029 & 5 &, 045 &, 025 \\
\hline \multirow[t]{3}{*}{ EXPRES. VERBAL } & 1 & 92,50 & 3,536 & 2 & & \\
\hline & 2 & 57,00 & 7,937 & 3 &, 010 & \\
\hline & 3 & 52,60 & 13,409 & 5 &, 004 & ,603 \\
\hline \multicolumn{7}{|l|}{ Edad } \\
\hline & 1 & 17,8849 & 2,03414 & 2 & & \\
\hline & 2 & 16,7790 & ,42693 & 3 & & \\
\hline & 3 & 16,9447 & 2,81988 & 5 & & \\
\hline & Total & 17,0830 & 2,05395 & 10 & & \\
\hline
\end{tabular}

res al grupo 3. Es decir, el grupo 1 tiene buen nivel tanto en comprensión como en expresión verbal, el grupo 2 es bueno en comprensión pero bajo en expresión y el grupo 3 es bajo en ambos aspectos del lenguaje.

\section{Conclusiones y discusión}

En primer lugar podemos afirmar que hay diferentes perfiles cognitivos dentro del SPW. Encontramos un grupo que presenta un CIV signifi- 
Tabla 2. Test Kruskal-Wallis de los 3 grupos de SPW en WISC-R e ITPA

\begin{tabular}{lcc}
\hline Pruebas & Chi $^{2}$ & Sig. \\
\hline WISC-R & & \\
\hline WISC_CIV & 6,1 &, 040 \\
WISC_CIM & 3,7 &, 150 \\
WISC_CIT & 4,8 &, 086 \\
SEMEJANZAS & 6,5 &, 037 \\
ARITMÉTICA & 7,4 &, 024 \\
COMPRENSIÓN & 7,9 &, 010 \\
CUBOS & 6,1 &, 040 \\
LABERINTOS & 7,1 &, 028 \\
\hline ITPA & & \\
\hline COMPR. AUDITIVA & 6,3 &, 039 \\
\hline
\end{tabular}

cativamente más alto que el resto, de hecho está dentro de la normalidad, que se correspondería con los sujetos con disomía uniparental descritos por Roof, Stone, MacLean, Feurer, Thompson y Butler (2000), Whittington, Holland, Webb, Butler, Clarke y Boer (2004), Walley y Donaldson (2005) y Abraldes et al. (2007). Al igual que en el trabajo de Roof et al. (2000) las mejores puntuaciones de este grupo se obtienen en los subtest de aritmética, vocabulario y comprensión pero no en el subtest de información.

En nuestro trabajo hemos intentado buscar además las características que diferencian a los sujetos con deleciones cortas y largas. Hemos encontrado tres grupos cognitivamente diferentes, cuyas características corresponden con bastante aproximación a las descritas por Butler, Bittel, Kibiryeva, Talebizadeh y Thompson (2004) para los tres principales formas genéticas del síndrome. Un primer grupo con un CIV superior y un CIM bajo que correspondería al grupo con disomía uniparental materna. Un segundo grupo, cuyos rendimientos los sitúan en el rango de una deficiencia mental ligera con un aumento no significativo del CIM, se aproxima en sus características a las descritas para las deleciones cortas, con la diferencia de que en lugar de presentar una máxima puntuación en rompecabezas nuestro grupo la presenta en cubos, lo que coincide con los hallazgos de Curfs, Wiegers, Sommers,
Borghgraef y Fryns (1991). El tercer grupo con puntuaciones muy bajas en todas las pruebas se acomoda a las características de la deleción larga.

Si nuestros grupos se corresponden con los grupos genéticos de SPW, los resultados obtenidos en el test de habilidades Psicolingüísticas (ITPA) sugieren trastornos de lenguaje característicos para cada tipo de alteración genética. Los sujetos con disomía uniparental no tendrían trastorno de lenguaje, la deleción corta podría cursar con un trastorno expresivo y la deleción larga tendría un trastorno del lenguaje tanto comprensivo como expresivo lo que significaría que en las 500 Kilobases de información genética que diferencian ambas deleciones habría genes que intervendrían en la comprensión del lenguaje. Análogamente entre los genes afectados en las deleciones cortas pero no afectados en las disomías uniparentales debería haber alguno que afectase al lenguaje expresivo.

Sin embargo si examinamos la tabla de los genes del cromosoma 15 en la zona afectada por el SPW (OMIM 2008) no encontramos ninguna mención al lenguaje pero sí al autismo. Se trata de un gen en $15 \mathrm{q} 11$ al que se atribuye susceptibilidad al autismo. La hipótesis que surge es si este gen predispone directamente al autismo o lo hace porque altera capacidades lingüísticas preferentemente las comprensivas. A una hipótesis parecida llegan Sahoo, Peters, Madduri, Glaze, German, Bird, BarbieriWelge, Bichell, Beaudet y Bacino (2006), quienes encuentran que hay cuatro genes principales implicados en los síndromes de Angelman y Prader-Willi que se afectan en las deleciones largas, pero no en las cortas. Según estos autores este es el motivo por el que en las deleciones largas pueden quedar más afectadas las capacidades verbales y aumentar la probabilidad de que se produzca autismo.

Tanto Roof et al. (2000) como Whittington et al. (2004), y Abraldes et al. (2007) observaron que dentro de los sujetos con deleción había algunos que tenían un CIM relativamente más alto que el resto, sin que esta diferencia llegase a ser estadísticamente significativa en ninguno de los trabajos citados. Walley y Donaldson (2005), por su parte, observan 
entre los sujetos con deleción, una tendencia a realizar mejor que el resto pruebas de tipo visoespacial. Nuestros resultados coinciden con estas observaciones ya que en el grupo 2 el CIM es 16 puntos superior a los otros dos. Tampoco en nuestro caso esta diferencia alcanza la significación estadística $(\mathrm{p}=0.09)$.

Los sujetos con deleción corta, tanto los reales de Butler et al. (2004) como los supuestos de nuestra muestra, destacan en sus capacidades manipulativas. Sin embargo el hecho es que todos los grupos de sujetos con SPW tienen capacidades manipulativas por debajo de la normalidad contrariamente a lo que se ha afirmado en algunos trabajos. Según estos resultados no se sostiene considerar que una buena habilidad en diferentes formas de rompecabezas es un indicador que apoya el diagnóstico del síndrome tal y como afirmaban Holm, Cassidy, Butler, Hanchett, Greenswag, Whitman y Greenberg (1993).

En la zona del cromosoma 15 afectada por el SPW podemos encontrar genes candidatos a explicar el descenso del cociente manipulativo. Los genes GABRB3, GABRA5 y GABRAG3, afectan a los receptores beta3, alfa5 y gamma3 del neurotransmisor GABA (ácido gamma-aminobutírico). Según los estudios realizados es probable que sea el GABA el responsable principal del deterioro de las capacidades visoespaciales en el SPW ya que estos sujetos tienen un aumento del GABA en plasma. Ebert, Schmidt, Thompson y Butler (1997) encontraron un nivel de 2 a 3 veces mayor en los sujetos con SPW que en el grupo control. Atribuyen esta elevación a una compensación debida a la falta de sensibilidad de los receptores GABA afectados por el daño genético. El exceso de GABA parece afectar a la memoria espacial. Helm, Haberman, Dean, Hoyt, Melcher, Luna y Gallagher (2005) han demostrado que los antagonistas gabérgicos de los receptores $\mathrm{GABAB}$ mejoran la memoria espacial.

La disregulación del sistema gabérgico en los síndromes de Prader - Willi y Angelman también ha sido observada en tomografías por emisión de positrones por Sundaram, Chugani y Chugani (2005). Esta disfunción del sistema gabérgico no solo afecta a la esfera cognitiva, sino que según Verhoeven y Tuinier (2006) puede llegar a producir estados psicóticos atípicos subagudos y anormalidades motoras que padecen entre un 20 y un $30 \%$ de los pacientes de este tipo.

\section{Implicaciones educativas}

Como el SPW es una enfermedad rara, las muestras de los trabajos son casi siempre reducidas. Sería interesante, por tanto, la repetición de trabajos sobre las características cognitivas, con el fin de realizar posteriormente un meta-análisis de la información obtenida para comprobar con mayor nivel de evidencia las características del síndrome. No obstante, creemos que los datos actuales permiten hacer recomendaciones educativas para los tres perfiles cognitivos principales. No es la meta de este trabajo la intervención en los trastornos conductuales y biológicos, nos centramos en la intervención cognitiva.

Existen grandes diferencias intelectuales entre los tres grupos genéticos por lo que la intervención educativa tendrá que tenerlas en cuenta. No obstante hay algunos rasgos que son comunes a todos y que condicionan su aprendizaje. Es corriente que todos los grupos de este síndrome presenten perseveraciones que se manifiestan, por ejemplo, en preguntas repetitivas sobre un mismo tema. Una posible actuación es devolverles la pregunta para que tomen conciencia de ella y les permita romper su círculo de repeticiones.

En los aspectos pragmáticos sus problemas fundamentales derivan de no acomodarse a intereses compartidos. Estas dificultades son un problema derivado del anterior, pues la atención perseverantemente centrada en sus intereses particulares les dificulta tener en cuenta al interlocutor. Seria adecuado trabajar con ellos desde la primera infancia los aspectos de atención compartida. También se debe prestar atención al desarrollo de habilidades sociales y otras conductas apropiadas para contribuir al éxito de la integración en la escuela, la comunidad y el hogar. 
Suelen presentar déficit en memoria visual espacial que condiciona su rendimiento manipulativo. Por ello se podría trabajar con juegos y con programas de ordenador orientados a estos objetivos.

Las dificultades para resolver problemas, para la abstracción o la generalización no dependen específicamente del síndrome sino, como sucede en general en la discapacidad intelectual, de su nivel cognitivo.

Los primeros trabajos publicados indicaban que las personas con el SPW presentan problemas del lenguaje, sin embargo los que tienen en cuenta la variabilidad genética, así como nuestros resultados, indican que los que padecen disomía uniparental poseen buenas habilidades lingüísticas. En cambio aquellos que presenta una deleción corta presentan problemas de lenguaje expresivo, por lo que requieren una intervención logopédica en este área. Las deleciones largas requieren una intervención generalizada en lenguaje, ya que están afectados tanto los aspectos comprensivos como expresivos. Un aspecto importante a tener en cuenta es que en los casos en las que las capacidades comprensivas están muy alteradas desde su inicio pueden favorecer la aparición de un cuadro de autismo. Ello hace necesario tomar precozmente medidas de prevención utilizando, si es necesario, sistemas de comunicación alternativa.

Existen personas con SPW con sorprendentes habilidades aritméticas, seguramente pertenecen al grupo de las disomías uniparentales que tienen mejor nivel verbal. Sin embargo en el resto esta capacidad esta claramente disminuida. Las causas son dispares: falta de comprensión de los enunciados, partes todo, perseveraciones y problemas espaciales. La intervención en estos casos tendrá que estar orientada a subsanar los déficit que predominen. Como en el resto de la discapacidad intelectual conviene que estos aprendizajes tengan una aplicación a la vida real lo que permite comprender mejor su significación.

Las capacidades de lectura y escritura varían ampliamente, dependiendo principalmente de su memoria visual y de las capacidades de integración visuales. En los grupos de menor nivel la compren- sión de textos puede ser muy literal y basada arbitrariamente en detalles, lo que puede ser debido a un déficit inferencial y del establecimiento de la relevancia que limita la comprensión de las implicaturas. Esto puede ser tratado dentro del entrenamiento en habilidades pragmáticas y mediante el entrenamiento del razonamiento lógico-causal.

\section{Referencias}

Abraldes, K., Torrado, M., Bin, L., Chertkoff, L., Baialardo, E. y Waisburg, H. (2007). Correlation study of cognitive profile and adaptative behabior in Prader Willi síndrome patients according to etiology. 6th International IPWSO Conference, Cluj-Napoca, Rumanía, 21-24 jun 2007.

Butler, M.G., Bittel, D.C., Kibiryeva, N., Talebizadeh, Z. y Thompson, T. (2004). Behavioral Diffe-rences Among Subjects With Prader-Willi Syn-drome and Type I or Type II Deletion and Maternal Disomy. Pediatrics, 113, 565-573.

Butler, M.G. (1995). High resolution chromosome analysis and fluorescence in situ hybridization in patients referred for Prader-Willi or Angelman syndrome. American Journal of Medical Genetics, 56, 420-422.

Conners, F.A., Rosenquist, C., J. Atwell, J. J. A. y Klinger, L.G. (2000). Cognitive Strengths and Weaknesses Associated with Prader-Willi Syndrome. Education and Training in Mental Retardation and Developmental Disabilities, 35, 441448.

Curfs, L.M., Wiegers, A.M., Sommers, J.R., Borghgraef, M., y Fryns, J.P. (1991). Strengths and weaknesses in the cognitive profile of youngsters with Prader-Willi syndrome. Clinical Genetics, 40, 430-434.

Ebert, M.H., Schmidt, D.E., Thompson, T. y Butler, M.G. (1997). Elevated plasma gamma-aminobutyric acid (GABA) levels in individuals with either Prader-Willi syndrome or Angelman syndrome. Journal of Neuropsychiatry and Clinical Neurosciences, 9, 75-80. 
Gross-Tsur, V., Landau, Y.E., Benarroch, F., WertmanElad, R. y Shalev, R.S. (2001). Cognition, attention, and behavior in Prader-Willi syndrome. Journal of Child Neurology. 16, 288-290.

Helm, K.A., Haberman, R.P., Dean, S.L., Hoyt E.C., Melcher, T., Lund, P.K. y Gallagher, M. (2005). GABAB receptor antagonist SGS742 improves spatial memory and reduces protein binding to the cAMP response element (CRE) in the hippocampus. Neuropharmacology, 48, 956-964.

Holm, V.A., Cassidy, S.B., Butler, M.G., Hanchett, J.M., Greenswag, L.R., Whitman, B.Y. y Greenberg, F. (1993). Prader-Willi syndrome: consensus diagnostic criteria. Pediatrics, 91, 398-402.

Mewborn, S. K., Milley, N. L., Fantes, J. A., Brown, R. L., Butler, M. G., Christian, S. L. y Ledbetter, D. H. (2002). Break point junction fragments in Prader-Willi and Angelman syndrome (PWS/AS) deletion patients reveal variable breakpoints within large duplicons. American Journal of Human Genetics, 71, A298.

Nicholls, R.D. y Knepper, J.L. (2001). Genome organization, function, and imprinting in PraderWilli and Angelman syndromes. Annual Review of Genomics and Human Genetics, 2, 153-175.

OMIM (Online Mendelian Inheritance in Man), Johns Hopkins University http://www.ncbi. nlm.nih.gov/Omim/getmap.cgi?d7221. 14/2/2008

Prader, A., Labhart, A. y Willi, H. (1956). Ein Syndrom von Adipositas, Kleinwuchs, Kryptochismus und Oligophrenie nach Myatonieatigem Zustand im Neugeborenenalter. Schweizerische medizinische Wochenschrift, 86, 1260-1261.

Roof, E., Stone, W., MacLean, W., Feurer, I.D.,
Thompson, T. y Butler, M.G. (2000). Intellectual characteristics of Prader-Willi syndrome: comparison of genetic subtypes. Journal of Intellectual Disability Research, 44, 25-30.

Sahoo, T., Peters, S.U., Madduri, N.S., Glaze, D.G., German, J.R., Bird, L.M., Barbieri-Welge, R., Bichell, T.J., Beaudet, A.L. y Bacino, C.A. (2006). Microarray based comparative genomic hybridization testing in deletion bearing patients with Angelman syndrome: genotype-phenotype correlations. Journal of Medical Genetics, 43, 512-516.

Sundaram, S.K., Chugani, H.T. y Chugani, D.C. (2005). Positron emission tomography methods with potential for increased understanding of mental retardation and developmental disabilities. Mental Retarded Developmental Disability Research Review, 11, 325-330.

Verhoeven, W.M. y Tuinier, S. (2006). Prader-Willi syndrome: atypical psychoses and motor dysfunctions. International Review of Neurobiology, 72, 119-130.

Walley, R.M. y Donaldson, M.D. (2005). An investigation of executive function abilities in adults with Prader-Willi syndrome. Journal of Intellect Disability Research, 49, 613-625.

Whittington, J., Butler, J.V. y Holland, A.J. (2007). Changing rates of genetic subtypes of Prader-Willi syndrome in the UK. European Journal of Human Genetics, 15, 127-130

Whittington, J., Holland, A., Webb, T., Butler, J., Clarke, D. y Boer H. (2004). Cognitive abilities and genotype in a population-based sample of people with Prader-Willi syndrome. Journal of Intellectual Disability Research, 48, 172-87.

Manuscrito recibido: $13 / 11 / 2009$

Revisión recibida: 15/01/2010

Manuscrito aceptado: 02/02/2010 